\title{
The Effects of A 6-Week Plyometric Training Programme on Sand Versus Wooden Parquet Surfaces on the Physical Performance Parameters of Well-Trained Young Basketball Players
}

\author{
Gokmen Ozen ${ }^{1}$, Ozdemir Atar ${ }^{2}$, Hurmuz Koc ${ }^{2}$ \\ Affiliations: 'Canakkale Onsekiz Mart University, Faculty of Sport Sciences, Department of Physical Education \\ and Sports Teacher Education, Canakkale, Turkey, ${ }^{2}$ Canakkale Onsekiz Mart University, Faculty of Sport Sciences, \\ Department of Coaching Education, Canakkale, Turkey
}

Correspondence: G. Ozen, Canakkale Onsekiz Mart University, Faculty of Sport Science, Canakkale Onsekiz Mart Universitesi Terzioğlu Yerleskesi Spor Bilimleri Fakultesi, 17100 Kepez/Canakkale Merkez/Canakkale, Turkey. E-mail: gokmenozen44@gmail.com

ABSTRACT The purpose of this study was to investigate the effect of plyometric training on sand and wooden parquet training surfaces on the physical performance parameters of young male basketball players. Twelve well-trained young male basketball players with age $17.58 \pm 0.5$ years, body mass $87.73 \pm 9.82 \mathrm{~kg}$, and height $193.75 \pm 7.02 \mathrm{~cm}$ were voluntarily involved in the study. All participants were grouped randomly as sand and wooden training groups. A six-week plyometric training programme was performed on the sand and wooden parquet surfaces. Anthropometric measurements and physical performance tests; vertical and standing long jump, box agility, and 30m sprint tests were performed. Data were collected before and after six weeks of plyometric training and were analysed using ANCOVA. The results indicated that the plyometric training programme significantly improved jumping, agility and $30 \mathrm{~m}$ sprint performance for both groups. Significant differences were found between the post-test mean values of two groups in the box-drill agility and $30 \mathrm{~m}$ sprint test scores $(\mathrm{p}<.05)$. The results of this study suggest that while the plyometric training performed on a wooden or sand surface does not cause a different effect on the improvement of jumping performance, plyometric training on the sand surface may be a more effective training surface to improve the agility and sprint performance of young players.

KEY WORDS athletic performance, basketball, plyometric training, sand, surface

$@$ MJSSMontenegro

EFFECTS OF PLYOMETRIC TRAINING ON DIFFERENT SURFACES

http://mjssm.me/?sekcija=article\&artid=189

Introduction

Basketball, which was invented in the USA at the end of the 19th century, is a team sport. The numbers of basketball players, coaches, and spectators have increased significantly since the 20th century (Nuñez \& Lyras, 2018). Today, basketball is a worldwide sport that is played by millions of people of all ages in many countries. It is one of the most popular sports branches in the USA, as well as European and Asian countries. Many leagues and tournaments, including the NBA and Euroleague, are organized every year (Paulauskas, Masiulis, Vaquera, Figueira, \& Sampaio, 2018).

Basketball is a dynamic team sport played at high speed and that incorporates physical, mental, technical, and tactical elements. Basketball players need to possess high-levels of motor abilities and athletic performance to be successful in matches and tournaments. (Ostojic, Mazic, \& Dikic, 2006). During a match, players demonstrate a variety of physical performance characteristics for specific movement patterns (dribbling, shooting, passing, throwing, rebounding blocking) and basic movement patterns (running, jumping, change of direction). The performance of basketball players is influenced by many factors, such as strength, speed, agility, endurance, and mobility. Therefore,

Received: August 062019 | Accepted after revision: September 28 2019 | First published online: March 012020

(c) 2020 by the author(s). License MSA, Podgorica, Montenegro. This article is an open access article distributed under the terms and conditions of the Creative Commons Attribution (CC BY).

Conflict of interest: None declared. 
different training models should be applied to players to develop their motor skills from an early age (Wissel, 2011).

Basketball requires a wide variety of physical fitness qualities. In particular, the leg strength and jumping ability of players play an essential role in basketball matches (Alemdaroğlu, 2012). Plyometric training (PT) was developed by Verkoshanski as a training method to improve explosive leg strength in sports. Also called "jump training" or "shock exercises", PT is a widely used training method to significantly improve jumping performance. PT is a unit of resistance training that increases the jumping capacity of athletes. Plyometric exercises (plyometrics), such as jumping, bounding, clapping push-up, and jump squats are used to increase the capacity of the muscle fibres to produce more tension and resultant force generation (Davies, Riemann, \& Manske, 2015; Verkoshanski, 1967). Prior studies have reported that PT has been demonstrated to be an effective training method for the improvement of leg strength, explosiveness, and power (Amrinder, Sakshi, \& Singh, 2014; Ramlan, Pitil, \& Wahed, 2018).

In the majority of sports, PT can cause improvement in athletic performance parameters, such as speed, agility, and power. However, many individual and environmental factors affect the performance of athletes in plyometric training (Davies et al., 2015). Many researchers have indicated that the level of effect on athletic performance in PT is influenced by the amount of energy returned to the athlete from the training surfaces, depending on the stiffness of the surface (Arazi \& Asadi, 2011; Impellizzeri et al., 2008). The recoil energy of the training surface together with the stretch-reflex cycle in PT affects the training efficiency. Therefore, the type of training surface plays an essential role in the effect of PT through the stretch-reflex mechanism (Ramlan et al., 2018).

Basketball games are usually played on wooden parquet or tartan surfaces. Thus, the players and coaches usually have a preference to train on these firm surfaces, but not preference different surfaces such as grass, sand or soil (Ozen, Koc, \& Aksoy, 2017). Scientific studies have indicated that training or playing on different surfaces affected basic physical skills such as running, jumping and hopping. Additionally, they have reported that the long-term sports training on different surfaces caused different metabolic adaptations in athletes (Gortsila, et al., 2013; Hardin, Van Den Bogert, \& Hamill, 2004; Martin et al., 2011, Ozen, Koc, \& Aksoy, 2017). Therefore, different training surfaces for PT may cause the different level improvement of physical performance parameters in basketball players. In this context, the effect of the training surface in PT on athletic performance is an issue to be investigated. To this end, we investigated the effect of PT on the sand and wooden parquet training surfaces on the physical performance parameters of young male basketball players.

\section{Methods}

\section{Participants}

Twelve highly trained young male basketball players with age $17.58 \pm 0.5$ years, body mass $87.73 \pm 9.82 \mathrm{~kg}$, and height $193.75 \pm 7.02 \mathrm{~cm}$ were voluntarily involved in the study. They were both healthy and regularly trained at least five years, three times a week for about 3-5 hours in every training session. Also, all of the participants belonged to the same competitive basketball team. The demographic characteristics of the participants are described in Table 1.

\begin{tabular}{lccc}
\multicolumn{2}{l}{ TABLE 1. Demographic Characteristics of Participants } & & \\
Variables & Min & Max & M \pm SD \\
\hline Age (year) & 17 & 18 & $17.58 \pm 0.504$ \\
Body Mass (kg) & 182 & 204 & $193.75 \pm 7.02$ \\
Height (cm) & 69.4 & 98.8 & $87.73 \pm 9.82$ \\
Body Fat (\%) & 8.3 & 17.4 & $12.22 \pm 2.93$ \\
Years of basketball experience & 4.0 & 9.0 & $6.4 \pm 2.63$ \\
\hline
\end{tabular}

\section{Study Procedure}

This study was carried out during the off-season period of the training year in Turkey. A single-blind randomized controlled trial design was used to determine the effect of a six-week PT on a dry sand surface and a wooden parquet surface. All participants were grouped randomly as PT sand (PTS) and PT wooden (PTW) groups. The six-week training programme was performed on a 20-cm-deep sand surface for PTS and a 10-cm-thick wooden parquet surface for PTW. Before the study commenced, the objectives, tests procedures and training programme of this study were explained to all participants and their parents. Signed informed consent was obtained from all participants as well as their parents. All subjects had experience of physical performance tests and PT. This study was conducted according to the criteria set by the Declaration of Helsinki and ethical standards in sport and exercise science research (Harriss \& Atkinson, 2011).

\section{Data Collection}

Anthropometric measurements; body mass, height and body fat (\%), and physical performance tests; vertical (VJ) and standing long jump (SLJ), box agility and $30 \mathrm{~m}$ sprint tests were performed to determine the effect of six-week PT on the physical performance of participants. Pre- and post-tests were carried out in an indoor sports hall with wooden parquet surface. First, baseline measurements and tests of participants were performed. Following baseline measurements, their post-intervention measurements and tests were performed after the end of the six-week plyometric training period. 


\section{Anthropometric measurements}

The body mass and standing heights of participants were measured using standardized techniques and calibrated equipment. These measurements were measured with participants in minimal clothing. Body mass (in $\mathrm{kg}$ ) was measured using a TANITA scale accurate to within $0.1 \mathrm{~kg}$. Height (in $\mathrm{cm}$ ) was measured using a stadiometer (Seca, Germany) accurate to within $0.1 \mathrm{~cm}$. Body fat (\%) was estimated with a bioelectrical impedance analysis (Tanita, Japan) after body height and chronological age were entered, and body mass was measured.

\section{Standing long jump (SLJ)}

The SLJ test was used to assess the long jump performance of participants. They were allowed a five-minute warmup before the standing long jump test. They were requested to stand behind the starting line marked, with feet together, and pushed off vigorously and jumped forward as far as they could. They were allowed to swing their arms during the test. The participant had to land with the feet together and to stay upright. The distance is measured from the take-off line to the point where the back of the heel nearest to the take-off line lands on the mat. The length of the jump was measured using a tape measure. This test was repeated two times with a one-minute rest between trials, and the better of the two trials was recorded.

\section{Vertical jump (VJ)}

The countermovement jump technique was used to assess the VJ performance of participants. After a 5-10 min warm-up that included submaximal running and jumping exercises, participants performed two trials of VJ test. The VJ test was measured by using a Takei digital jump meter device (Takei, Japan). The belt of digital jump meter, which connected to the elastic mat by a cord, was fitted to the participants. VJ tests were performed after each player was requested to jump as high as possible. Each test was performed two times with a one-minute rest between the trials. The best VJ performance of participants was recorded.

\section{Agility test}

The Box agility test was used to evaluate the ability to turn in different directions and body control. This test included four different movement stiles: running forward, shuffle, backpedal, turn, and sprint. A stopwatch, measuring tape, and four marker cones were used as test equipment. This test was made on a non-split floor. Four marker cones were placed $9.14 \mathrm{~m}$ apart in a square configuration. Before the start of the test, researchers gave verbal instructions explaining the test procedures. A participant started by getting down in a three-point stance next to the 1st cone. Upon the command "go", the timer would begin, and the participant started from the first cone sprinting to the 2nd cone, between 2 nd cone and the 3 rd he shuffled, between the 3 rd cone and the 4th cone, he backpedalled, and after passing the fourth cone turned and sprinted to the 1st cone. Measurements were recorded to the second.

\section{$30 \mathrm{~m}$ Sprint tests}

The participants performed two maximum $30 \mathrm{~m}$ sprints on the wooden parquet court. Participants performed the $30 \mathrm{~m}$ sprint test after a 10-minute warm-up that included submaximal running. Sprint times were measured using an electronic timing system. Each sprint test was repeated two times, separated by three minutes of passive recovery, and the best sprint performance was recorded.

\section{Training Protocol}

Following the literature (Miller, Herniman, Ricard, Cheatham, \& Michael, 2006; Ramirez-Campillo et al., 2019) a six-week PT programme was developed to determine the effect of PT on the sand surface on physical parameters of basketball players. During the study period, the participants were not participating in any competitive sport or similar exerted effort. All participants were asked not to change the current training programme or increase the training volume during the period of the study. Plyometric training sessions were performed: three training sessions per week with a two-day break to allow for adequate recovery between training in accordance with the suggestion of researchers. In the training sessions, $40 \mathrm{~cm}$ plyo-

\begin{tabular}{lccc} 
TABLE 2. The 6-Week Plyometric Training Program. & & \\
Plyometrics & $\begin{array}{c}\text { Weeks 1-2 } \\
\text { (repetitions } \mathbf{x} \text { sets) }\end{array}$ & $\begin{array}{c}\text { Weeks 3-4 } \\
\text { (repetitions } \mathbf{x} \text { sets) }\end{array}$ & $\begin{array}{c}\text { Weeks 5-6 } \\
\text { (repetitions } \text { x sets) }\end{array}$ \\
\hline VJ & $8 \times 3$ & $10 \times 3$ & $12 \times 3$ \\
SLJ & $8 \times 3$ & $10 \times 3$ & $12 \times 3$ \\
UCJ & $8 \times 3$ & $10 \times 3$ & $12 \times 3$ \\
$180^{\circ}$ jumps & $8 \times 3$ & $10 \times 3$ & $12 \times 3$ \\
RCJ & $8 \times 3$ & $10 \times 3$ & $12 \times 3$ \\
BJ & $8 \times 3$ & $10 \times 3$ & $12 \times 3$ \\
DJ & $8 \times 3$ & $10 \times 3$ & $12 \times 3$ \\
\hline Total number of contact (volume) & 168 & 210 & 252 \\
\hline
\end{tabular}

Note. VJ-vertical jump, SLJ - standing long jump, UCJ - unilateral countermovement jumping, RCJ - repeated countermovement jumping, BJ - board jumping, DJ - drop jumps. 
metric boxes and hurdles were used as the PT equipment. Plyometric exercises were performed on wooden parquet surface for the PTW group and on a $0.2 \mathrm{~m}$ deep dry sand surface for the PTS group. Each PT session included the VJ, SLJ, unilateral countermovement jumping (UCJ), $180^{\circ}$ jumping, repeated countermovement jumping (RCJ), board jumping (BJ), and drop jumps (DJ) exercises. The six-week PT training programme is presented in Table 2 .

\section{Statistical Analysis}

Statistical analyses were carried out using SPSS statistic software package (version 15.0, SPSS Inc., Chicago, IL, USA). Data are presented as means with a standard deviation $(\mathrm{M} \pm \mathrm{SD})$. The Shapiro-Wilk W test was used to determine that data was acceptable with regard to homogeneity. As variances showed a normal distribution, a Paired t-tests were used for within-group comparisons. An analysis of covariance (ANCOVA) with the pretest value as the covariate was performed to compare the effects of sand and wooden parquet surfaces of plyometric training between PTS and PTW groups for posttest values. For all analyses, the level of statistical significance was set at 0.05 .

\section{Results}

The pretest and posttest mean values of the PTS and PTW groups were presented in Table 3. The results of the present study indicated that a six-week PT programme significantly improved VJ, SLJ, agility, and 30m sprint performance for both PT groups $(\mathrm{p}<.05)$. However, there was no significant difference in body mass and body fat mass percentage following the six-week PT programme $(\mathrm{p}>.05)$.

\begin{tabular}{lcccc}
\hline \multicolumn{1}{c}{ TABLE 3. Effect of 6-Week Plyometric Training on Physical Performance Parameters of PTS and PTW } \\
\multicolumn{1}{c}{ Variables } & Group & $\begin{array}{c}\text { Pre-test } \\
\text { M } \pm \text { SD }\end{array}$ & $\begin{array}{c}\text { Post-test } \\
\text { M } \pm \text { SD }\end{array}$ & $\begin{array}{c}\text { Pre-post } \\
\text { Mean Difference }\end{array}$ \\
\hline \multirow{2}{*}{ Body Mass (kg) } & PTS & $87.73 \pm 9.82$ & $86.54 \pm 9.78$ & -1.17 \\
\multirow{2}{*}{ Body Fat (\%) } & PTW & $86.94 \pm 8.32$ & $86.17 \pm 8.66$ & -0.77 \\
& PTS & $12.22 \pm 2.93$ & $11.54 \pm 2.91$ & -0.68 \\
VJ (cm) & PTW & $11.87 \pm 2.51$ & $11.14 \pm 2.36$ & -0.73 \\
& PTS & $54.92 \pm 6.61$ & $63.34 \pm 6.03^{*}$ & 8.58 \\
SLJ (cm) & PTW & $55.73 \pm 6.82$ & $65.42 \pm 6.21^{*}$ & 9.69 \\
\multirow{2}{*}{ Box Drill Agility (sec) } & PTS & $171.75 \pm 9.50$ & $184.83 \pm 9.08^{*}$ & 13.08 \\
& PTW & $173.87 \pm 9.41$ & $185.52 \pm 8.19^{*}$ & 11.65 \\
$30 \mathrm{~m}$ Sprint (sec) & PTS & $15.61 \pm 1.42$ & $14.12 \pm 1.36^{*} \mathbf{t}$ & -1.49 \\
& PTW & $15.92 \pm 1.87$ & $14.82 \pm 1.56^{*}$ & -1.10 \\
\hline
\end{tabular}

Note: ${ }^{*}-p<.05$ (Significantly different within group, between pretest ant posttest); $\neq-p>.05$ (Significantly different than posttest between two groups).

When comparing pretest data (baseline values) in between PT groups, there were no statistically significant differences in the baseline mean values of PTS and PTW ( $p>.05)$. When the pretest scores of PTS and PTW groups were controlled as covariates, significant differences were found between the post-test mean values of two groups in the box-drill agility $(\mathrm{F}(2,10)=3.67, \mathrm{p}=0.027)$ and $30 \mathrm{~m}$ sprint test scores $(\mathrm{F}(2,10)=5.69, \mathrm{p}=$ 0.014). After six weeks of training, agility, and 30m sprint ability of PTS was significantly more improved as compared with that of the PTW group.

\section{Discussion}

PT is a training method commonly used for improving agility, sprint, and jumping performances in young and adult basketball players (Khlifa et al., 2010; Palma-Muñoz et al., 2018). However, some researchers have determined that the effectiveness of plyometrics on these performance parameters may vary with the training conditions (Impellizzeri et al., 2008; Ramirez-Campillo et al., 2019). Training surfaces are one of the most important environmental variables for PT (Arazi, Eston, Asadi, Roozbeh, \& Saati Zarei, 2016). It is essential to examine the effect of different training surfaces in basketball considering that basketball training sessions are frequently performed on tartan or wooden parquet surface. Thus, we sought to determine the influence of PT performed on wooden parquet and sand surface on agility, sprint, and jumping performance of young basketball players.

Based on the results of the present study, significant enhancements were found in the post-tests of agility, $30 \mathrm{~m}$ sprint, VC and SLJ performance in both groups. These findings revealed that the PT was effective in developing these performance parameters of the young basketball players irrespective of the training surfaces. This is in good agreement with the results of the previous studies for the PT (Bavli, 2012; Nikolic, 2018). This finding has been confirmed in many previous studies examining the effect of PT on athletic performance on 
different training surfaces, such as grass, concrete, sand, and tartan. In this context, the improvement of physical performance after the six-week PT programme in this study may be ascribed to the increasing muscular strength and capacity of positive energy production due to utilizing the recoil of elastic energy stored (Amrinder, Sakshi, \& Singh, 2014; Impellizzeri et al., 2008; Ramlan et al., 2018). In contrast, in comparing their body weight and fat percentage, there were no significant differences between pre and post-test values. In agreement with our findings, some researchers also have reported that there were no changes in the body fat percentage, body mass, and body composition after PT programs (Campo et al., 2009; Luebbers et al., 2003) equalized for training volume, followed by a 4 -week recovery period of no plyometric training on anaerobic power and vertical jump performance. Physically active, college-aged men were randomly assigned to either a 4 -week $(\mathrm{n}=19$, weight $=73.4+/-7.5 \mathrm{~kg}$. It may be said that PT does not significantly distinguish young basketball players' body weights and fat ratios in spite of the fact that PT has positive effects on their agility, sprint and jumping performance.

When comparing the differences between the posttest values of PTS and PTW groups, our analysis demonstrated that there were no significant differences in the jumping performance. Even though VJ and SLC performance of both groups after six-weeks of PT intervention was significantly higher than their baseline values, the different training surface did not cause a difference in the jumping performance development of athletes. Similarly, several studies reported that meaningful differences were found in the between pre and post-test scores of VJ and SLJ performance after PT performed on different training surfaces but no difference in between posttest scores of these groups (Arazi, Mohammadi, \& Asadi, 2014; Bavli, 2012). Taken together, these results indicated that the different training surfaces for plyometrics did not cause a considerable difference to improve the jumping performance that required explosive power.

In contrast, it was found that the box agility and $30 \mathrm{~m}$ sprint performances of PTS group were significantly more improved than the PTW group. A possible explanation for these effects of plyometric exercises on the soft surfaces is it requires a stronger concentric push-off phase, which was caused by a reduction of the potential elastic energy and the difficulty of the ankle to push along the vertical axis due to sand absorption (Ramlan et al., 2018). Moreover, doing exercise on sand cause a higher level of physiological strain experienced than on firmer surfaces, such as tartan, concrete, wood (Binnie, Dawson, Pinnington, Landers, \& Peeling, 2014). Scientific evidence demonstrates that when athletes are exposed to high levels of physiological strain, they might gain more muscular strength and endurance. Therefore, the sports training on the sand surface has the potential for more improvement in the muscular strength and endurance compared to training on firmer surfaces. In this connection, having the higher box agility and $30 \mathrm{~m}$ sprint performances of PTS group may be explained by the fact that they gain higher level muscular strength and endurance than the PTW group during the training programme. In addition, these differences between athletes may be a result of this, and the box agility and sprint tests require more muscular endurance capacity than the jump tests which required explosive power.

\section{Conclusions}

The results from this study confirmed the well-known benefits of PT in agility, jumping and sprint performance of young basketball players. These results show that enhances in agility, jumping, and sprint performance can occur in as little as six weeks of PT, performed on both sand and a wooden training surface. Our key finding is the box agility and $30 \mathrm{~m}$ sprint performances of PTS group were significantly more improved than those of the PTW group. Overall, the results of this study suggest that while PT performed on a wooden or sand surface does not cause a different effect on the improvement of jumping performance, PT on the sand surface may be a more effective training surface to improve agility and sprint performance of young players. Accordingly, plyometric training on sand can be considered an effective option within the yearly training plan for coaches to enhance sprint and agility performance in young basketball players. Future studies have to examine the underlying physiological dimensions of PTs performed on different surfaces.

\section{References}

Alemdaroğlu, U. (2012). The relationship between muscle strength, anaerobic performance, agility, sprint ability and vertical jump performance in professional basketball players. Journal of Human Kinetics, 31, 149-158. doi: 10.2478/v10078-012-0016-6

Amrinder, S., Sakshi, G., \& Singh, S. J. (2014). Effect of plyometric training on sand versus grass on muscle soreness and selected sportspecific performance variables in hockey players. Journal of Human Sport and Exercise, 9(1), 59-67. doi: 10.4100/jhse.2014.91.07

Arazi, H., \& Asadi, A. (2011). The effect of aquatic and land plyometric training on strength, sprint, and balance in young basketball players. Journal of Human Sport \& Exercise, 6(1), 101-111. do1: 10.4100/ jhse.2011.61.12

Arazi, H., Eston, R., Asadi, A., Roozbeh, B., \& Saati Zarei, A. (2016). Type of Ground Surface during Plyometric Training Affects the Severity of Exercise-Induced Muscle Damage. Sports, 4(1), 15. doi: $10.3390 /$ sports 4010015

Arazi, H., Mohammadi, M., \& Asadi, A. (2014). Muscular adaptations to depth jump plyometric training: Comparison of sand vs. land surface. Interventional Medicine and Applied Science, 6(3), 125-130. doi: 10.1556/IMAS.6.2014.3.5 
Bavli, O. (2012). Comparison the Effect of Water Plyometrics and Land Plyometrics On Body Mass Index and Biomotorical Variables of Adolescent Basketball Players. International Journal of Sport and Exercise Science, 4(1), 11-14.

Binnie, M. J., Dawson, B., Pinnington, H., Landers, G., \& Peeling, P. (2014). Sand training: A review of current research and practical applications, Journal of Sports Sciences, 32(1), 8-15. doi: $10.1080 / 02640414.2013 .805239$

Campo, S. S., Vaeyens, R., Philippaerts, R. M., Redondo, J. C., De Benito, A. M., \& Cuadrado, G. (2009). Effects of lower-Limb plyometric training on body composition, explosive strength, and kicking speed in female soccer players. Journal of Strength \& Conditioning Research, 23(6), 1714-1722. doi: 10.1519/ JSC.0b013e3181b3f537

Davies, G., Riemann, B. L., \& Manske, R. (2015). Current concepts of plyometric exercise. International Journal of Sports Physical Therapy, 10(6), 760-786

Gortsila, E., Theos, A., Nesic, G., \& Maridaki, M. (2013). Effect of training surface on agility and passing skills of prepubescent female volleyball players. Journal of Sports Medicine \& Doping Studies, 3(2), 1-5

Hardin, E. C., van den Bogert, A. J., \& Hamill, J. (2004). Kinematic adaptations during running: effects of footwear, surface, and duration. Medicine \& Science in Sports \& Exercise, 36(5), 838-844.

Harriss D.J., \& Atkinson G. (2011). Ethical standards in sport and exercise science research. International Journal of Sports Medicine, 32(11), 819-821. doi: 10.1055/s-0043-124001

Impellizzeri, F. M., Rampinini, E., Castagna, C., Martino, F., Fiorini, S., \& Wisloff, U. (2008). Effect of plyometric training on sand versus grass on muscle soreness and jumping and sprinting ability in soccer players, British Journal of Sports Medicine, 42(1), 42-46.

Khlifa, R., Aouadi, R., Hermassi, S., Chelly, M. S., Jlid, M. C., Hbacha, H., \& Castagna, C. (2010). Effects of a plyometric training program with and without added load on jumping ability in basketball players. Journal of Strength \& Conditioning Research, 24(11), 2955-29651. doi: 10.1519/JSC.0b013e3181e37fbe

Luebbers, P. E., Potteiger, J. A., Hulver, M. W., Thyfault, J. P., Carper, M. J., \& Lockwood, R. H. (2003). Effects of Plyometric Training and Recovery on Vertical Jump Performance and Anaerobic Power. Journal of Strength \& Conditioning Research, 17(4), 704-709. do1: 10.1097/00005768-200305001-01514

Palma-Muñoz, I., Ramírez-Campillo, R., Azocar-Gallardo, J., Álvarez, C., Asadi, A., Moran, J., \& Chaabene, H. (Ahead of Print). Effects of Progressed and Nonprogressed Volume-Based Overload Plyometric Training on Components of Physical Fitness and Body Composition Variables in Youth Male Basketball Players. Journal of Strength \& Conditioning Research. doi: 10.1519/JSC.0000000000002950

Paulauskas, R., Masiulis, N., Vaquera, A., Figueira, B., \& Sampaio, J. (2018). Basketball game-related statistics that discriminate between European players competing in the NBA and in the Euroleague. Journal of Human Kinetics, 65, 225-233. doi: 10.2478/hukin-2018-0030

Ramirez-Campillo, R., Álvarez, C., García-Pinillos, F., García-Ramos, A., Loturco, I., Chaabene, H., \& Granacher, U. (2019). Effects of Combined Surfaces vs. Single-Surface Plyometric Training on Soccer Players' Physical Fitness. Journal of Strength \& Conditioning Research, 20(4), 740-744. doi: 10.1519/ JSC.0000000000002929

Ramlan, M. H., Pitil, P. P., \& Wahed, W. J. E. (2018). Effects of plyometric training on grass surface and concrete surface on jumping performance among volleyball athletes. Malaysian Journal of Movement, Health \& Exercise, 7(2), 127-134.

Martin, C., Thevenet, D., Zouhal, H., Mornet, Y., Delès, R., Crestel, T., Ben, A.A., \& Prioux, J. (2011). Effects of playing surface (hard and clay courts) on heart rate and blood lactate during tennis matches played by high-level players. Journal of Strength \& Conditioning Research, 25(1), 163-170. doi: 10.1519/ JSC.0b013e $3181 \mathrm{fb} 459 \mathrm{~b}$

Miller, M. G., Herniman, J. J., Ricard, M. D., Cheatham, C. C., \& Michael, T. J. (2006). The effects of a 6-week plyometric training program on agility. Journal of Sports Science and Medicine, 5(3), 459-465.

Nikolic, A. (2018). Plyometric basketball training. Turkısh journal of kınesıology, 4(4), 101-105. do1:10.31459/ turkjkin.468867

Nuñez, P. D. P., \& Lyras, A. (2018). Basketball, Innovation and Change Agency: Historical Overview and Current Landscape. Sport and Olympic-paralympic Studies Journal, 3(1), 155-163.

Ostojic, S. M., Mazic, S., \& Dikic, N. (2006). Profiling in basketball: Physical and physiological characteristics of elite players. Journal of Strength \& Conditioning Research, 20(4), 740-744.

Ozen, G., Koc, H., \& Aksoy, C. (2017). Long-term effects of different training surfaces on anaerobic power and leg strength in athletes. Kinesiologia Slovenica, 23(1), 25-32.

Verkoshanski Y. (1967). Are depth jumps useful? Track and Field Magazine. 12(9), 75-78.

Wissel, H. (2011). Basketball: Steps to success. Champaign, IL: Human Kinetics. 